\title{
Giant nonfunctioning adrenal tumors: two case reports and review of the literature
}

\author{
George Chatzoulis, loannis Passos*, Dimitra-Rafailia Bakaloudi, Dimitrios Giannakidis, Alexandros Koumpoulas, \\ Konstantinos Ioannidis, Ioannis Tsifountoudis, Dimitrios Pappas and Panagiotis Spyridopoulos
}

\begin{abstract}
Background: There are an estimated 1-2 cases per million per year of adrenocortical carcinoma in the USA. It represents a rare and aggressive malignancy; it is the second most aggressive endocrine malignant disease after anaplastic thyroid carcinoma. Non-secretory adrenal masses are diagnosed late due to a mass effect or metastatic disease or found incidentally (adrenal incidentalomas).

Case presentation: The first case report describes a 39-year-old Greek woman who presented to our department with complaints of repeated symptoms of flatulence and epigastric discomfort over a few months. The second case report is about a 67-year-old Greek woman who presented to our department after being evaluated for fatigue, mass effect, and epigastric discomfort. Both of them were diagnosed as having a nonfunctioning adrenocortical carcinoma and underwent open adrenalectomy.

Conclusions: Approximately $60 \%$ of patients with adrenocortical carcinoma present with symptoms and signs of hormonal secretion. Our cases' adrenocortical carcinomas were not functional. Hormone secretion is not a discriminating feature between benign and malignant adrenocortical masses. The silent clinical nature of nonfunctioning adrenocortical carcinoma results in late diagnosis, while the majority of patients present with locally advanced and/or metastatic disease. Adrenocortical carcinoma is a rare endocrine tumor with a poor prognosis that can be diagnostically challenging and demands high clinical suspicion. The work-up for adrenal masses must include determination of whether the mass is functioning or nonfunctioning and whether it is benign or malignant.
\end{abstract}

Keywords: Nonfunctioning, Adrenal tumors, Adrenocortical carcinoma (ACC), Adrenalectomy, Case report, Hormone secretion

\section{Background}

There are an estimated 1-2 cases per million per year of adrenocortical carcinoma (ACC) in the USA [1]. ACC represents a rare and aggressive malignancy [1]; it is the second most aggressive endocrine malignant disease after anaplastic thyroid carcinoma. ACC is more common in the female population; it has a bimodal age distribution of 5 to 20 years and 40 to 50 years [2]. Out of all the adrenal masses, 60\% are hyper-functioning (hormone-secreting) and the rest, $40 \%$, are nonfunctioning (non-hormone secreting) [3].

Functional ACC can clinically manifest early with virilization, feminization, or Cushing's syndrome, while non-secretory adrenal masses are diagnosed late and incidentally (adrenal incidentalomas) due to a mass effect or metastatic disease [4]. Nonfunctioning ACC is correlated with a poor prognosis due to the late diagnosis, local invasion, or recurrence and distant metastases $[1,3,4]$.

On the other hand, adrenal cysts are usually benign lesions with a discovery at autopsy range of $0.064-0.18 \%$, in which adrenal pseudocysts account for an extremely small amount [4].

We present the cases of two women who were referred to our Department of surgery and were diagnosed as having a large nonfunctioning ACC. Both women underwent open adrenalectomy.

* Correspondence: ioannispassos@gmail.com

Department of Surgery, 424 General Military Hospital of Thessaloniki, Agiou

Nikolaou 42, 55132, Kalamaria, Thessaloniki, Greece

(c) The Author(s). 2018, corrected publication November 2018. Open Access This article is distributed under the terms of the Creative Commons Attribution 4.0 International License (http://creativecommons.org/licenses/by/4.0/), which permits

unrestricted use, distribution, and reproduction in any medium, provided you give appropriate credit to the original author(s) and the source, provide a link to the Creative Commons license, and indicate if changes were made. The Creative Commons Public Domain Dedication waiver (http://creativecommons.org/publicdomain/zero/1.0/) applies to the data made available in this article, unless otherwise stated. 


\section{Case presentation \\ Case 1}

A 39-year-old Greek woman, a nurse in our military hospital, presented to our department with repeated symptoms of flatulence and epigastric discomfort over a few months. Her past medical, social, environmental, and family history was unremarkable for any illness or causative factor. She was not on any medication, she did not smoke tobacco or consume alcohol, and she was afebrile at the time of admission. Her neurological examination was normal; her blood pressure was 126/ $84 \mathrm{mmHg}$, her pulses were regular at $75-80$ beats $/ \mathrm{mi}$ nute, and her temperature was $36.8{ }^{\circ} \mathrm{C}$. Laboratory testing revealed the following results that are shown in Table 1: a rise in erythrocyte sedimentation rate (ESR) and C-reactive protein (CRP) inflammation markers as well as a rise in her lactate dehydrogenase (LDH) tissue necrosis index (Table 1).

A computed tomography (CT) scan showed a large mass measuring approximately $24 \mathrm{~cm}$ in its greatest dimension $(23.7 \mathrm{~cm} \times 16.5 \mathrm{~cm} \times 11.5 \mathrm{~cm})$ that originated from her right adrenal gland and occupied her right abdomen, while compressing her right hepatic lobe and her inferior vena cava, and it was in contact with the right perirenal fascia of Gerota (Figs. 1 and 2).

A functional adrenal work-up was performed and included: measurement of serum aldosterone, potassium, renin, and adrenocorticotrophic hormone levels; a dexamethasone suppression test; and measurement of 24-hour urinary metanephrine levels. All results were within the reference ranges. A fine-needle core biopsy revealed ACC.

A metastatic work-up included CT scans of her head and chest and a bone scan and they were negative for metastases. During laparotomy the giant tumor was

Table 1 Laboratory testing for case report 1

\begin{tabular}{lll}
\hline Test & Result & Reference range \\
\hline Hematocrit (\%) & 34 & $37-47$ \\
WBC (white blood cells) $\times 10^{9} / \mathrm{L}$ & 11,100 & $4-11,000$ \\
PLT (platelet count) $\times 10^{3} / \mu \mathrm{L}$ & 503 & $142-450$ \\
ESR (mm) & 67 & $<20$ \\
Glucose (mg/dl) & 112 & $70-105$ \\
Urea (mg/dl) & 19 & $20-45$ \\
Creatinine (mg/dl) & 0.6 & $0.72-1.25$ \\
Uric acid (mg/dl) & 3.3 & $3-7.2$ \\
YGT (U/L) & 67 & $9-36$ \\
CPK (U/L) & 22 & $25-110$ \\
LDH (lactate dehydrogenase; U/L) & 418 & $125-220$ \\
CRP (C-reactive protein; mg/dl) & 6.8 & $<0.5$ \\
\hline
\end{tabular}

CPK creatine phosphokinase, ESR erythrocyte sedimentation rate, $\gamma G T$ gamma-glutamyltransferase removed completely with its own capsule, without the need for excision of adherent organs as there were no infiltrations.

Postoperative pathology results confirmed the diagnosis of ACC and no further adjuvant treatment was applied to our patient (Fig. 3). Her postoperative course has been uneventful for 1.5 years.

\section{Case 2}

A 67-year-old Greek woman, a retired high-school teacher, presented to our department after an evaluation for fatigue, mass effect, epigastric discomfort in liver cirrhosis, and hypothyroidism. Her past medical history was also remarkable for arterial hypertension. She was on double anti-hypertensive medication and she was also receiving levothyroxine $100 \mu \mathrm{G}$ once daily. She was a heavy tobacco smoker (>1pack/day) for 35 years and a social alcohol consumer. She was afebrile at the time of admission. Her neurological examination was normal; her blood pressure was 145/ $97 \mathrm{mmHg}$, her pulses were 95 beats/minute, and her temperature was $36.4{ }^{\circ} \mathrm{C}$. Her mother died from breast cancer.

Laboratory testing revealed results that are shown in Table 2. A CT scan revealed a large invasive mass in the anatomical area of her left adrenal gland, well circumscribed, measuring $7 \times 7 \times 9 \mathrm{~cm}$; it extended to the upper pole of her left kidney and the inner hilum of her spleen without infiltration of the above organs, which showed marked heterogeneous enhancement after intravenous infusion of a contrast agent, which posed a differential diagnosis problem with possible pheochromocytoma (Fig. 4).

Further laboratory testing of post-prandial plasma cortisol and plasma testosterone levels gave normal results, mimicking a nonfunctional left ACC. Elective open adrenalectomy was scheduled without any complications and the postoperative pathology record was consistent with a pseudocyst, without evidence of malignancy (Figs. 4 and 5). She has had an uneventful course 1 year postoperatively.

\section{Discussion}

The overall 5-year survival rate of ACC ranges from 16 to $44 \%$ [4]. However, a more recent study recorded a 5-year overall survival rate that reached $60 \%$ and concerned patients with a $34 \%$ range of synchronous metastatic disease. Positive prognostic factors that could improve overall survival are early-stage disease in the absence of lymph node and distant metastases, an age of $<40$ years, and negative resection margins (Ro), as in our case $[1,4]$.

On the other hand, adrenal pseudocysts are cystic lesions surrounded by a fibrous tissue wall with an absence 


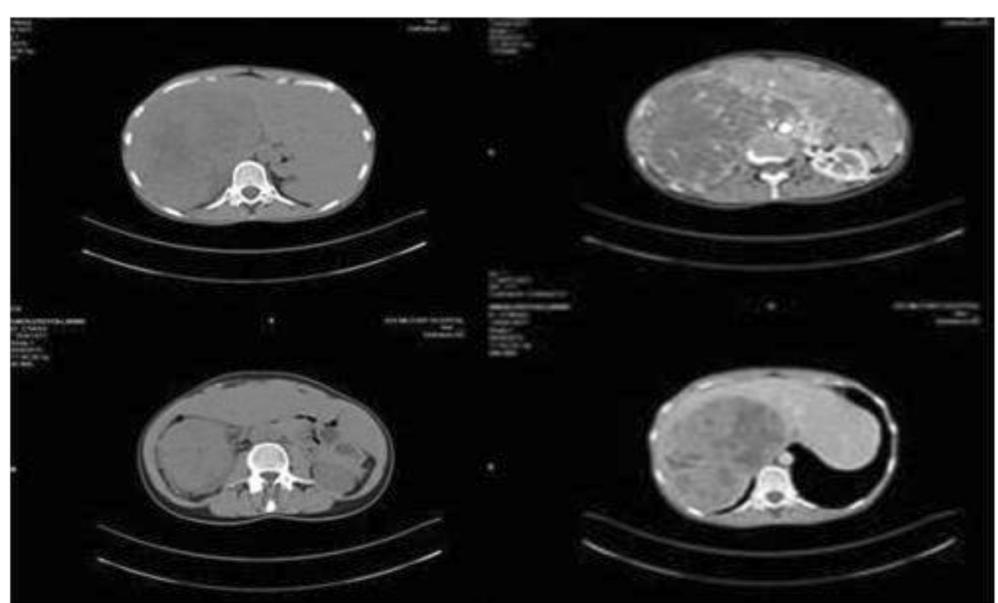

Fig. 1 Computed tomography appearance of giant adrenocortical carcinoma

of a recognizable epithelial or endothelial lining layer that characterizes true cysts. Adrenal pseudocysts are associated with malignant $\mathrm{ACC}$ in $7 \%$ of cases [5].

Approximately $60 \%$ of patients with ACC present with symptoms and signs of hormonal secretion. Our cases' ACC were not functional. Hormone secretion is not a discriminating feature between benign and malignant adrenocortical masses. The silent clinical nature of nonfunctioning ACC results in poor outcomes, while the majority of patients present with locally advanced and/or metastatic disease. The work-up for adrenal masses must include determination of whether the mass is functioning or nonfunctioning and whether it is benign or malignant $[1,5]$.

Radiographic studies in the form of CT or magnetic resonance imaging (MRI) can help define the size of the mass and rule out metastases. Emerging evidence suggests that fluorodeoxyglucose positron emission tomography (FDG-PET) with CT is superior to CT alone [6]. However, FDG-PET/CT is still considered a complementary study and is not recommended for ACC work-up [6].

Large tumors of $>4 \mathrm{~cm}$ raise high clinical suspicion of malignancy, as in our cases, and favor radical adrenalectomy $[7,8]$. To the best of our knowledge, the first of

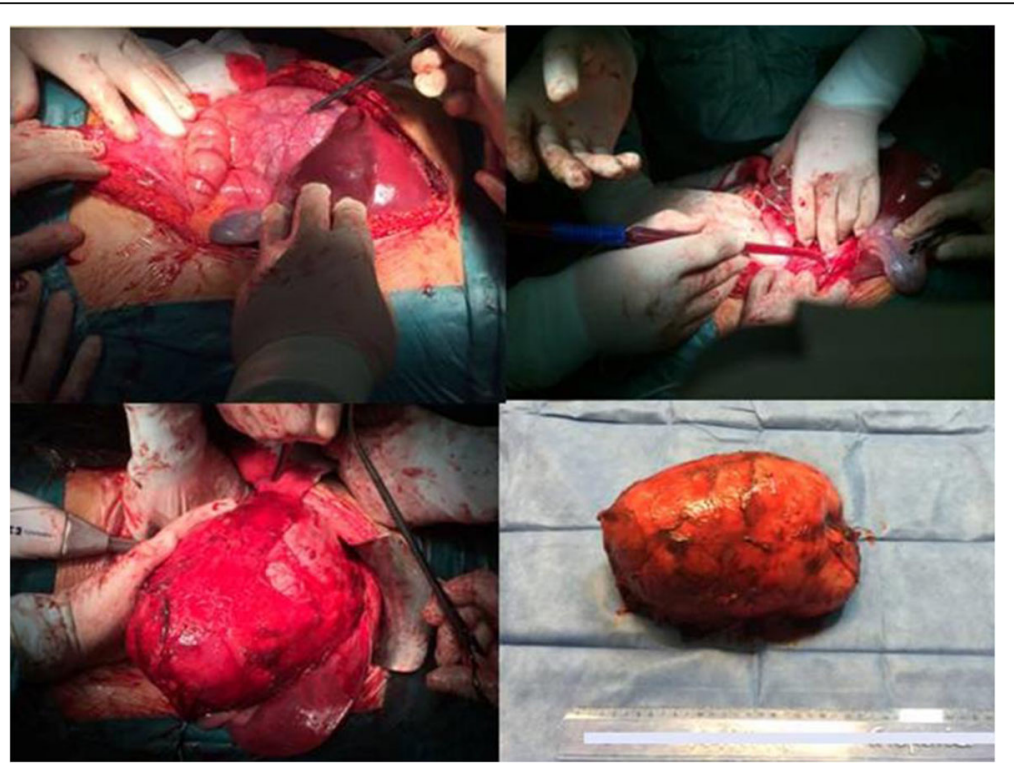

Fig. 2 Intraoperative image of giant adrenocortical carcinoma with displacement of right hepatic lobe to the left and vena cava close to the anterior abdominal wall 


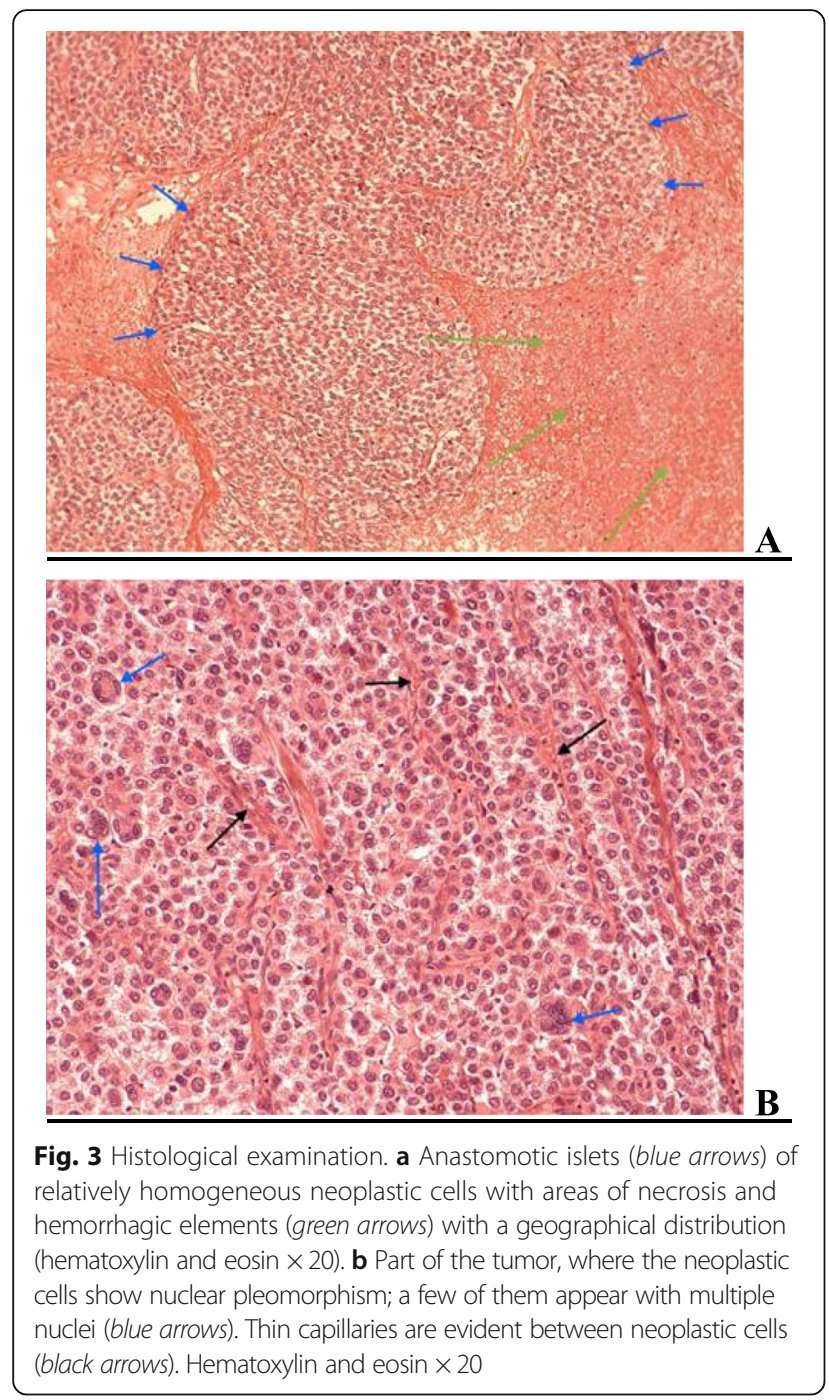

Table 2 Laboratory testing for case report 2

\begin{tabular}{lll}
\hline Test & Result & Reference range \\
\hline Hematocrit (\%) & 40.3 & $37-47$ \\
WBC (white blood cells) $\times 10^{9} / \mathrm{L}$ & 5600 & $4-11,000$ \\
PLT (platelet count) $\times 10^{3} / \mathrm{LL}$ & 145 & $142-450$ \\
ESR (mm) & 48 & $<20$ \\
Glucose (mg/dl) & 117 & $70-105$ \\
Urea (mg/dl) & 33 & $20-45$ \\
Creatinine (mg/dl) & 0.88 & $0.72-1.25$ \\
Uric acid (mg/dl) & 7.5 & $3-7.2$ \\
YGT (U/L) & 39 & $9-36$ \\
CPK (U/L) & 35 & $25-200$ \\
LDH (lactate dehydrogenase; U/L) & 276 & $125-220$ \\
CRP (C-reactive protein; mg/dl) & 0.6 & $<0.5$ \\
\hline CPK creatre &
\end{tabular}

CPK creatine phosphokinase, ESR erythrocyte sedimentation rate, $\gamma G T$ gamma-glutamyltransferase our two case reports describes one of the largest nonfunctioning ACCs reported in the literature in the past 10 years.

Despite the poor prognosis in this patient group, chemotherapy has a limited role in the treatment of ACC, and surgical resection has been shown to have the best outcomes $[9,10]$. However, recent studies have shown a role for adjuvant chemotherapy in prolonging recurrence-free survival and overall survival [11]. There is no established duration of adjuvant chemotherapy.

Allolio et al. considered that complete surgical resection (Ro excision) offers the best chance for long-term survival in patients with stage I-III ACC, although these patients should be candidates for chemo-irradiation in order to increase disease-free survival [12]. In cases of recurrence, surgery should be considered a first-line option. However, mitotane has a valuable role in stage IV cases or in the presence of recurrent disseminated disease $[12,13]$.

Studies demonstrated mitotane's associated toxicity and its ability in: (1) inhibition of adrenocortical steroid biosynthesis by inhibiting cholesterol side chain cleavage and $11 \beta$-hydroxylation, and (2) induction of hepatic clearance affecting extra-adrenal disposition of cortisol [14]. Concerning the routine use of mitotane, there is a lot of controversy as partial response occurs for 5-30\% of patients with ACC treated with this anticancer agent. High-risk patients are currently being treated for 5 years with mitotane.

Alternatively, in patients with proven lung metastasis, the published evidence suggests that en bloc excision of involved organs and pulmonary metastasectomy could improve overall survival.

Postoperative surveillance for recurrence should be performed every 3 months for the first 2 years and then every 6 months for 5 years.

Adrenal pseudocysts most commonly arise from hemorrhage within the adrenal gland, secondary to extreme stress, birth, trauma, surgery, or malignancy. The differential diagnosis of adrenal pseudocysts is from endothelial epithelial and parasitic cysts and rarely from mesothelial cysts, lymphangiomas, dermoid cysts, or cystic adrenal carcinomas.

Most pseudocysts on CT reveal well-demarcated, round or oval masses with fluid density with content of septa, blood, and soft tissue components. The wall of a pseudocyst seems to have occasional calcification on CT. MRI is pathognomonic for visualizing the complicated intracystic components [15].

Regarding surgical treatment, the open approach is preferable if the patient is symptomatic, the mass is $>6$ $\mathrm{cm}$, or there is a possibility of malignancy. Laparoscopic surgery is indicated for small tumors or pseudocysts provided there is no peri-adrenal infiltration and subsequent capsular disruption $[15,16]$. 


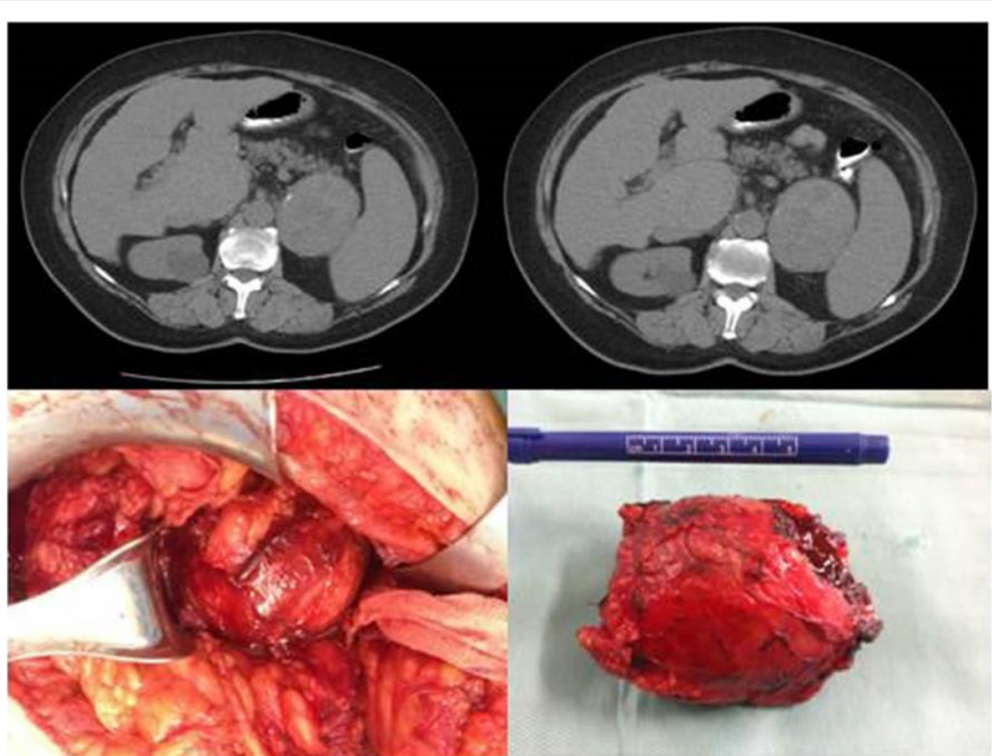

Fig. 4 Computed tomography and intraoperative findings of left adrenal pseudocyst

\section{Conclusions}

ACC is a rare and aggressive malignancy. Non-secretory adrenal masses are diagnosed late by a mass effect, metastatic disease, or found incidentally. The work-up for adrenal masses must include determination of whether the mass is functioning or nonfunctioning and whether it is benign or malignant.

We present the cases of two women who presented to our department after being evaluated for fatigue, mass effect, and epigastric discomfort. Both of them were diagnosed as having a nonfunctioning ACC and underwent open adrenalectomy. To the best of our knowledge, the first case's nonfunctioning ACC is considered to be one of the biggest that has ever been described in the literature.

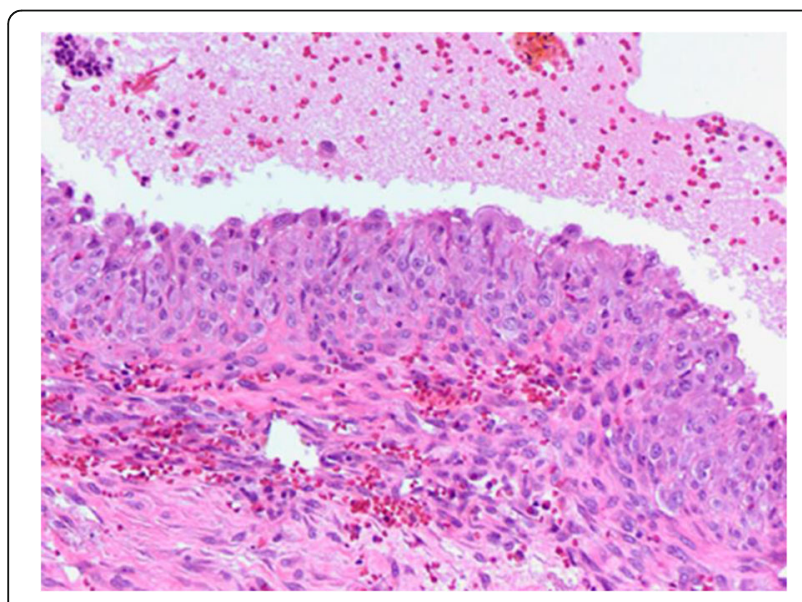

Fig. 5 Histological examination: single-stranded cyst with fibrous wall, without epithelial lining, with adherent tissue of adrenal tissue, confirming the diagnosis of adrenal pseudocyst. Hematoxylin and $\operatorname{eosin} \times 20$

\section{Availability of data and materials}

The data and materials/figures used in the current study are available from the corresponding author on reasonable request.

\section{Authors' contributions}

GC wrote and corrected the manuscript for its scientific basis. IP wrote the manuscript and collected the data. D-RB and DG collected the data for the study. AK revised the manuscript for grammar and syntax mistakes. KI was one of the consultant surgeons who operated on these cases. IT provided the radiographic/CT images. DP did the histopathological analysis. PS is the director of the Department of Surgery and the consultant surgeon who provided the cases. All authors read and approved the final manuscript.

\section{Ethics approval and consent to participate}

Our case report obtained ethics approval from the ethics committee of our hospital and the patients gave their informed consent to participate.

\section{Consent for publication}

Written informed consent was obtained from the patients for publication of this case report and any accompanying images. A copy of the written consents is available for review by the Editor-in-Chief of this journal.

\section{Competing interests}

The authors declare that they have no competing interests.

\section{Publisher's Note}

Springer Nature remains neutral with regard to jurisdictional claims in published maps and institutional affiliations.

Received: 5 May 2018 Accepted: 8 October 2018

Published online: 10 November 2018

\section{References}

1. Almarzouq A, Asfar S, Hussain S, Al-Hunayan A, Aldousari S. Giant nonfunctioning adrenocortical carcinoma: a case report and review of the literature. BMC Res Notes. 2014;31:7.

2. Bacalbasa N, Terzea D, Jianu V, Marcu M, Stoica C, Balescu I. Multiple visceral resection for giant non-secretory adrenocortical carcinoma in an elderly patient: a case report. Anticancer Res. 2015;35(4):2169-74.

3. Patel W, Shah DS, Raychaudhari CR, Patel KB. Giant non-functioning adrenocortical carcinoma: A rare childhood tumor. Indian J Med Paediatr Oncol Off J Indian Soc Med Paediatr Oncol. 2010;31(2):65-8. 
4. Vassilopoulou-Sellin R, Schultz PN. Adrenocortical carcinoma. Clinical outcome at the end of the 20th century. Cancer. 2001;92:1113.

5. Wilkinson M, Fanning DM, Moloney J, Flood H. Giant adrenal pseudocyst harbouring adrenocortical cancer. BMJ Case Rep. 2011;2011. doi: 10.1136/ bcr.05.2011.4169.

6. Deandreis D, Leboulleux S, Caramella C, Schlumberger M, Baudin E. FDG PET in the management of patients with adrenal masses and adrenocortical carcinoma. Horm Cancer. 2011;2:354.

7. Weiss LM. Comparative histologic study of 43 metastasizing and nonmetastasizing adrenocortical tumors. Am J Surg Pathol. 1984;8:163-9.

8. Kapoor A, Morris T, Rebello R. Guidelines for the Management of the Incidentally Discovered Adrenal Mass. Can Urol Assoc J. 2011;5(4):241-7.

9. Ayala-Ramirez M, Jasim S, Feng L, Ejaz S, Deniz F, Busaidy N, Waguespack SG, Naing A, Sircar K, Wood CG, Pagliaro L, Jimenez C, Vassilopoulou-Sellin R, Hebra MA. Adrenocortical Carcinoma: Clinical Outcomes and prognosis of 330 Patients at a Tertiary Care Center. Eur J Endocrinol. 2013;169:891-9.

10. Schulick RD, Brennan MF. Long-Term Survival After Complete Resection and Repeat Resection in Patients With Adrenocortical Carcinoma. Ann Surg Oncol. 1999;6:719-26.

11. Kemp C, Ripley R, Mathur A, Steinburg SM, Nguyen DM, Fojo T, Schrump DS. Pulmonary Resection for Metastatic Adrenocortical Carcinoma: The National Cancer Institute Experience. Ann Thorac Surg. 2011;92(4):1195-200.

12. Allolio B, Hahner S, Weismann D, Fassnacht M. Management of adrenocortical carcinoma. Clin Endocrinol. 2004;60:273-87.

13. Polavarapu HV, Casillas S, Edmonds P, Lim PS, Pezzia CM. Adrenocortical Carcinoma: Complete Surgical Resection After 18 Years. World J Oncol. 2011;2(6):307-10

14. Huang H, Fojo T. Adjuvant Mitotane for Adrenocortical Cancer-A Recurring Controversy. J Clin Endocrinol Metab. 2008;93(10):3730-2.

15. Momiyama M, Matsuo K, Yoshida K, Tanaka K, Akiyama H, Yamanaka S, Endo I. A giant adrenal pseudocyst presenting with right hypochondralgia and fever: a case report. J Med Case Rep. 2011;5:135.

16. Karim L, Larkin D, Sadat M. Examine the patient not the hernia: identification of an asymptomatic giant primary retroperitoneal pseudocyst. A case report and literature review. J Surg Case Rep. 2016;2016(5)

Ready to submit your research? Choose BMC and benefit from:

- fast, convenient online submission

- thorough peer review by experienced researchers in your field

- rapid publication on acceptance

- support for research data, including large and complex data types

- gold Open Access which fosters wider collaboration and increased citations

- maximum visibility for your research: over $100 \mathrm{M}$ website views per year

At $\mathrm{BMC}$, research is always in progress.

Learn more biomedcentral.com/submissions 